\title{
Diagnostic mutational analysis of MECP2 in Korean patients with Rett syndrome
}

\author{
In-Joo Kim, Yeon-Joo Kim², \\ Byeong-Hee Son ${ }^{5}$, Sang-Ook $\mathrm{Nam}^{3}$, \\ Hoon-Chul Kang ${ }^{6}$, Heung-Dong $\mathrm{Kim}^{7}$, \\ Mi-Ae $\mathrm{Yoo}^{8}$, Ook-Hwan $\mathrm{Choi}^{2,9,10}$ \\ and Cheol-Min Kim ${ }^{1,4,9,11}$ \\ ${ }^{1}$ Department of Biochemistry \\ ${ }^{2}$ Department of Obstetrics and Gynecology \\ ${ }^{3}$ Department of Pediatrics \\ ${ }^{4}$ Biomedical Informatics Unit, College of Medicine \\ Pusan National University \\ Busan 602-739, Korea \\ ${ }^{5}$ Department of Pediatrics, St. Benedict Hospital \\ Busan 601-731, Korea \\ ${ }^{6}$ Department of Pediatrics, Epilepsy Center \\ College of Medicine, Inje University \\ Sang-gye Paik Hospital \\ Seoul 139-707, Korea \\ ${ }^{7}$ Department of Pediatrics \\ College of Medicine, Yonsei University
}

Severance Hospital, Handicapped Children's Research Institute

Brain Research Institute

Seoul 139-707, Korea

${ }^{8}$ Department of Molecular Biology

College of Natural Science, Pusan National University

Busan 609-735, Korea

${ }^{9}$ Medical Research Institute

Pusan National University Hospital

Busan 602-739, Korea

${ }^{10}$ Co-corresponding author: E-mail, ohchoi@pusan.ac.kr

${ }^{11}$ Corresponding author: Tel, 82-51-240-7725;

Fax, 82-51-248-1118; E-mail, kimcm@pusan.ac.kr

Accepted February 202006

Abbreviations: HDAC, histone deacetylases; MBD, methyl-CpG binding domain; MECP2, methyl-CpG binding protein 2; NLS, nuclear localization signal; RTT, Rett syndrome; SNP, single nucleotide polymorphism; TRD, transcriptional repression domain; WDR, group II WW domain binding region

\section{Abstract}

Rett syndrome (RTT) is an X-linked dominant neurodevelopmental disorder affecting 1 per 10,000 15,000 female births worldwide. The disease-causing gene has been identified as MECP2 (methyl-
CpG-binding protein 2). In this study, we performed diagnostic mutational analysis of the MECP2 gene in RTT patients. Four exons and a putative promoter of the MECP2 gene were analyzed from the peripheral blood of 43 Korean patients with Rett syndrome by PCR-RFLP and direct sequencing. Mutations were detected in the MECP2 gene in approximately $60.5 \%$ of patients (26 cases/43 cases). The mutations consisted of 14 different types, including 9 missense mutations, 4 nonsense mutations and 1 frameshift mutation. Of these, three mutations (G161E, T311M, p385fs X409) were newly identified and were determined to be disease-causing mutations by PCRRFLP and direct sequencing analysis. Most of the mutations were located within MBD (42.3\%) and TRD (50\%). T158M, R270X, and R306C mutations were identified at a high frequency. Additionally, an intronic SNP (IVS3 + 23C > G) was newly identified in three of the patients. IVS3 $+23 C>G$ may be a disease-related and Korea-specific SNP for RTT. L100V and A201V are apparently disease-causing mutations in Korean RTT, contrary to previous studies. Disease-causing mutations and polymorphisms are important tools for diagnosing RTT in Koreans. The experimental procedures used in this study should be considered for clinical molecular biologic diagnosis.

Keywords: DNA mutational analysis; diagnosis; MECP2 protein, human; polymorphism, restriction fragment length; Rett syndrome

\section{Introduction}

Rett syndrome (RTT, MIM No. 312750) is an X-linked dominant neurodevelopmental disorder and is the second most common cause of mental retardation in females, following Down syndrome (Rett, 1966; dos Santos et al., 2005). The vast majority of cases of RTT (more than $99 \%$ ) are sporadic occurrences and familial recurrences are rare (Hoffbuhr et al., 2001).

RTT is caused by mutations in a gene encoding the methyl-CpG binding protein 2 (MECP2, AF30876) (Amir et al., 1999). MECP2 is mapped between IRAK (interleukin-1 receptor associated kinase) and $R C P$ (red opsin gene) loci on chromosome $\mathrm{Xq} 28$ (Reichwald et al., 2000). It is $76 \mathrm{~kb}$ in size and is 
composed of 486 amino acids. The four exons of human MECP2 have a combined length of $1775 \mathrm{bp}$. MECP2 participates in transcriptional silencing by binding to methylated DNA in nucleosomes and chromatin. It contains functional domains, a methyl-CpG binding domain (MBD) of 85 amino acids that binds to methylated $\mathrm{CpG}$ islands, and a transcriptional repression domain (TRD) of 104 amino acids that interacts with the transcriptional repressor $\operatorname{Sin} 3 A$, which recruits histone deacetylases (HDAC) (Van den Veyver and Zoghbi, 2000). In addition, MECP2 has a nuclear localization signal (NLS) (Jorgensen and Bird, 2002) and a group II WW domain binding region (WDR) (Buschdorf and Stratling, 2004; Weaving et al., 2005). The function of NLS within the TRD location is to facilitate the transport of MECP2 into the nucleus.

There are only a few reports regarding mutational analysis of MECP2 in Koreans because the overall understanding of RTT is limited (Chae et al., 2002). To compare the pattern of MECP2 mutations in Koreans with RTT from worldwide reports, we performed mutational analysis in Korean RTT patients and control subjects. Direct DNA sequencing was used and results were confirmed by PCR-RFLP.

\section{Materials and Methods}

\section{DNA samples from RTT patients}

Whole blood samples $(500 \mu \mathrm{l})$ from 43 sporadic RTT patients (41 females and 2 males) were collected in EDTA tubes. All patients were phenotypically cla- ssical RTT. Genomic DNA was extracted using an E.Z.N.A. blood DNA kit (Omega Bioteck Inc. Norcross).

\section{PCR amplification}

The putative promoter and four exons of the MECP2 gene were amplified by PCR by dividing exon 2 into two parts, exon 3 into two parts, and exon 4 into five parts. Primer sequences designed by Amir et al. (1999) were used, except for the putative promoter and exon 1. The sequence of the promoter and exon 1 were 5'-gggTgCAATgAAACgCTTA-3' (forward) and 5'-TTTACCACAgCCСТCTCTCC-3' (reverse).

\section{Direct sequencing}

The PCR products were cleaned using a QIAquick gel extraction kit (QIAGEN, Hiden, Germany). The sequencing primers were the same as those for PCR. The DNA sequencing results were compared with the normal DNA sequence (AF030876).

\section{RFLP analysis}

We used the GeneTyx program to investigate the restriction enzyme sites. Dde I (New England Biolabs Co., MA) was used to detect G161E. BsmB I (New England Biolabs.) was used to detect T311M. A mismatch PCR technique was used to determine if the L100V is a disease-causing mutation. A second new reverse primer of exon 3 for the L100V mutation was designed (5'-GCTTAAGCTTCCGTGTCCAGCCTTCAGGTA-3'). The primer sequence for mismatch PCR is underlined. The PCR product for

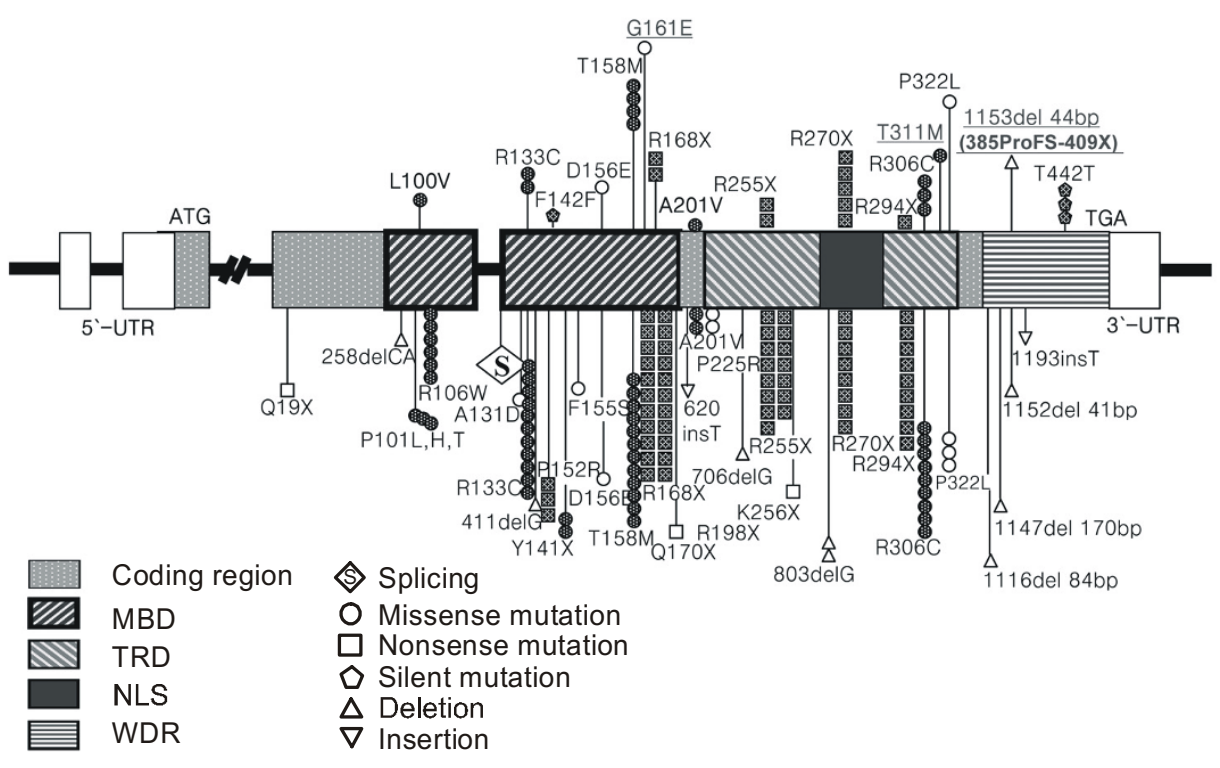

Figure 1. Distribution of $M E C P 2$ mutations in RTT. Top: Mutations identified in this study. Novel mutations are indicated by bold underlined type. Bottom: mutations described previously (MECP2 variation database of InterRETT and RettBASE) (Fyfe et al., 2003). Circles $(\bigcirc, \otimes)$ represent missense mutations and squares $(\square$, 㷎) represent nonsense mutations. Mutations at $\mathrm{CpG}$ dinucleotides are shown by filled circles ( ) or squares ( $)$. Frequency is indicated by the number of symbols (Buyse et al., 2000; Miltenberger-Miltenyi and Laccone, 2003; Fukuda et al., 2005; Oexle et al., 2005). 

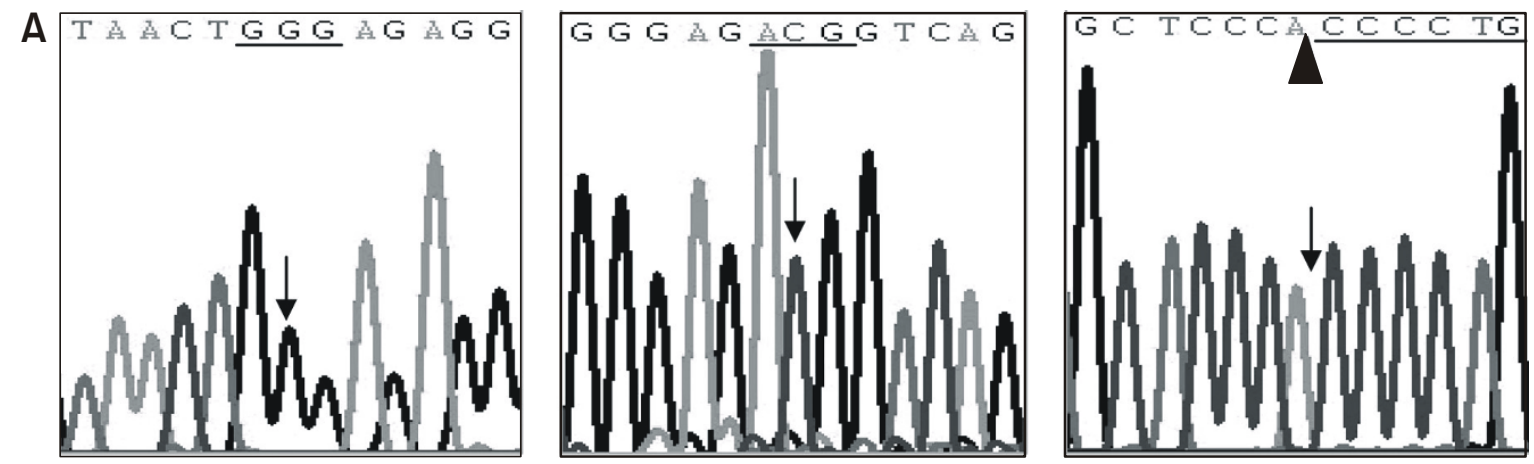

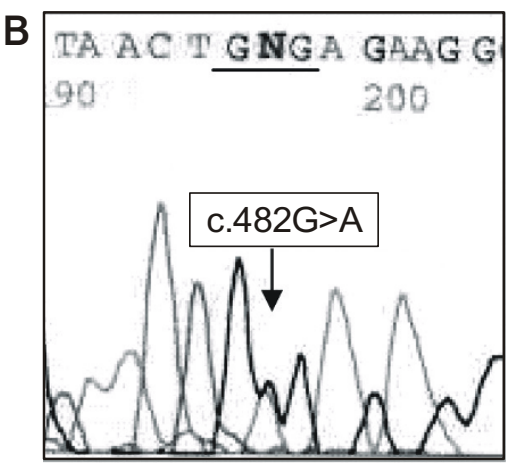

p.G161E

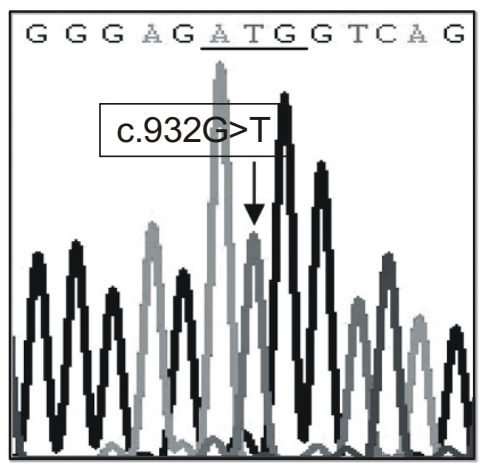

p.T311M

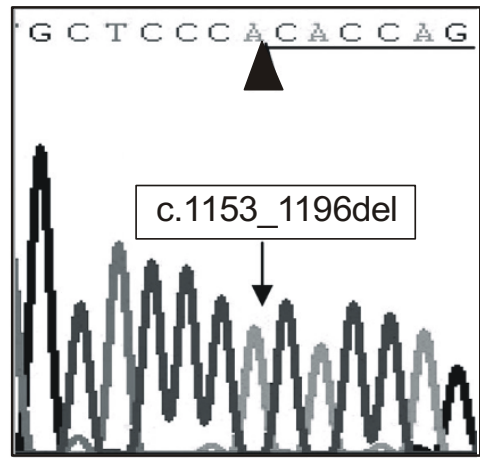

p.P385fs $\times 409$

Figure 2. DNA sequencing electropherograms of wild type (A) and novel mutations (B) of MECP2 identified in RTT patients in this study. Substituted nucleotides are indicated by arrows and substituted amino acids are underlined. Deletion sites are indicated by arrowheads. All sequences are in the sense orientation. The mutation P385fs X409 was identified by sequencing after cloning.

L100V in the MECP2 gene created an Afa I (Takara, Tokyo, Japan) restriction site. A201V created a Bal I (Takara) restriction site. Restriction digested products were separated by electrophoresis on either $2 \%$ agarose gel or $4 \%$ NuSieve gel (FMC, Rockland) (Bedia et al., 2003; Kim et al., 2004).

\section{Results}

\section{Mutational analysis of MECP2}

To investigate mutation of the MECP2 gene, we analyzed a promoter and four exons of $M E C P 2$ in 43 RTT patients by direct sequencing. The amplified PCR product contained an intron and an exon. MECP2 mutations were detected in $26(60.5 \%)$ of the 43 patients. These results were compared with the MECP2 variation database for InterRETT and RettBASE (Fyfe et al., 2003). The mutations consisted of 14 different types, including 9 missense mutations, 4 nonsense mutations, and 1 frameshift mutation. Most of these mutations were located within MBD (42.3\%) and TRD (50\%) (Figure 1). Of the mutations identified, three $(\mathrm{G} 161 \mathrm{E}, \mathrm{T} 311 \mathrm{M}$,
P385fs X409) were new (Figure 2). Three mutations, T158M (9.3\%), R270X (11.6\%), and R306C (7\%), were identified with a high frequency (Table 1). The two male patients with different RTT phenotypes did not have any identifiable mutations. Two silent mutations (F142F, T442T) that had been reported previously (Miltenberger-Miltenyi and Laccone, 2003) were also found. These accompanied other mutations in three of the four patients with $\mathrm{F} 142 \mathrm{~F}$ and T442T.

\section{Confirmation of the mutations}

To confirm the novel sequence changes, RFLP analysis was performed for G161E and T311A (Table 1) and direct sequencing was performed for p385fsX409. The G161E (c.482G $>$ A) mutation created a Dde I site while the wild type had $241 \mathrm{bp}$ and $129 \mathrm{bp}$ fragments, and the heterozygotic mutant had $241 \mathrm{bp}, 202 \mathrm{bp}, 129 \mathrm{bp}$, and $39 \mathrm{bp}$ fragments (Figure $3 \mathrm{~A}$, lane 5 and 6 ). The T311A (c.932C $>\mathrm{T}$ ) mutation destroyed the BsmB I site. The $366 \mathrm{bp}$ product was digested into $198 \mathrm{bp}$ and $168 \mathrm{bp}$ fragments in the wild type (Figure $3 \mathrm{~A}$, lane 8 ), whereas patients with T311A exhibited a single band 
Table 1. Summary of MECP2 mutations and sequence variants in RTT patients

\begin{tabular}{|c|c|c|c|c|c|c|c|}
\hline Mutation type & Domain & Exon & $\begin{array}{l}\text { Nucleotide } \\
\text { change }^{a}\end{array}$ & $\begin{array}{l}\text { Amino acid } \\
\text { change }^{a}\end{array}$ & Frequency $^{\mathrm{b}}$ & $\begin{array}{l}\text { Restriction } \\
\text { enzyme }^{\mathrm{e}}\end{array}$ & Patients \\
\hline \multirow{9}{*}{$\begin{array}{l}\text { Missense } \\
\text { mutations }\end{array}$} & MBD & Exon3(2) & c. $298 \mathrm{C}>\mathrm{G}$ & p.L100V & $2.3 \%$ & Afa I(+) & $\mathrm{R} 21$ \\
\hline & MBD & Exon4(1) & c. $397 \mathrm{C}>\mathrm{T}$ & p.R133C & $4.7 \%$ & & $\mathrm{R} 8,35$ \\
\hline & MBD & Exon4(1) & c. $468 \mathrm{C}>\mathrm{G}$ & p.D156E & $2.3 \%$ & & R24 \\
\hline & MBD & Exon4(1) & c. $473 \mathrm{C}>\mathrm{T}$ & p.T158M & $9.3 \%$ & & $\mathrm{R} 6,11,12,19$ \\
\hline & MBD & Exon4(1) & $c .482 G>A$ & p.G161E ${ }^{c}$ & $2.3 \%$ & Dde I(+) & $\mathrm{R} 13$ \\
\hline & IDR & Exon4(1) & c. $602 \mathrm{C}>\mathrm{T}$ & p.A201V & $2.3 \%$ & $\mathrm{Ball}(+)$ & $\mathrm{R} 20$ \\
\hline & TRD & Exon4(3) & c. $.916 \mathrm{C}>\mathrm{T}$ & p.R306C & $7.0 \%$ & & $\mathbf{R 4}, 30,33$ \\
\hline & TRD & Exon4(3) & c. $932 \mathrm{C}>\mathrm{T}$ & p.T311M ${ }^{\mathrm{C}}$ & $2.3 \%$ & BsmB I(-) & $\mathrm{R} 28$ \\
\hline & WDR, C-term. & Exon4(3) & c. $.965 \mathrm{C}>\mathrm{T}$ & p.P322L & $2.3 \%$ & & $\mathrm{R} 16$ \\
\hline \multirow{4}{*}{$\begin{array}{l}\text { Nonsense } \\
\text { mutations }\end{array}$} & MBD & Exon4(1) & c. $502 \mathrm{C}>\mathrm{T}$ & p.R168X & $4.7 \%$ & & $\mathrm{R} 5,7$ \\
\hline & TRD & Exon4(2) & c. $763 \mathrm{C}>\mathrm{T}$ & p.R255X & $4.7 \%$ & & $\mathrm{R} 9,14$ \\
\hline & TRD, NLS & Exon4(3) & c. $.808 \mathrm{C}>\mathrm{T}$ & p.R270X & $11.6 \%$ & & $\mathrm{R} 15,23,25,31,38$ \\
\hline & TRD & Exon4(3) & c. $880 \mathrm{C}>\mathrm{T}$ & p.R294X & $2.3 \%$ & & R36 \\
\hline Frameshift & WDR, C-term. & Exon4(4) & c.1153_1196del & p.P385fs $X 409^{\mathrm{c}}$ & $2.3 \%$ & & R37 \\
\hline \multirow{2}{*}{$\begin{array}{l}\text { Silent } \\
\text { mutations }\end{array}$} & MBD & Exon4(1) & c. $426 \mathrm{C}>\mathrm{T}$ & p.F142 $F^{d}$ & $2.3 \%$ & & R4 \\
\hline & WDR, C-term. & Exon4(4) & c. $1326 \mathrm{C}>\mathrm{T}$ & p.T442T ${ }^{d}$ & $7.0 \%$ & & R7, 17, 25 \\
\hline SNP & & Intron3 & IVS3 $+23 C>G$ & & $7.0 \%$ & & R15, 24, 34 \\
\hline
\end{tabular}

${ }^{a}$ Nucleotides and amino acids are numbered according to GenBank. ${ }^{b}$ Frequency of substitution among 43 Korean patients with classical RTT. ${ }^{c}$ Three novel mutations were identified in this study. ${ }^{d}$ The nucleotide is substituted, but the amino acid is silent. ${ }^{\mathrm{e}}$ Restriction enzyme sites for RFLP analysis were created (+) or destroyed (-) by novel mutations and sequence variants of the MECP2 gene in RTT patients. The description of the sequence variant was based on the work of den Dunner and Antonarakis $(2000 ; 2001)$. The patients indicated by bold type exhibited two types of nucleotide changes.

A

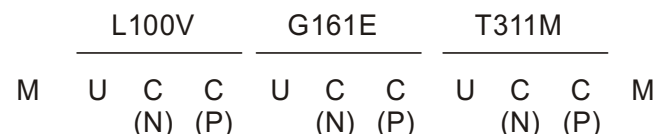

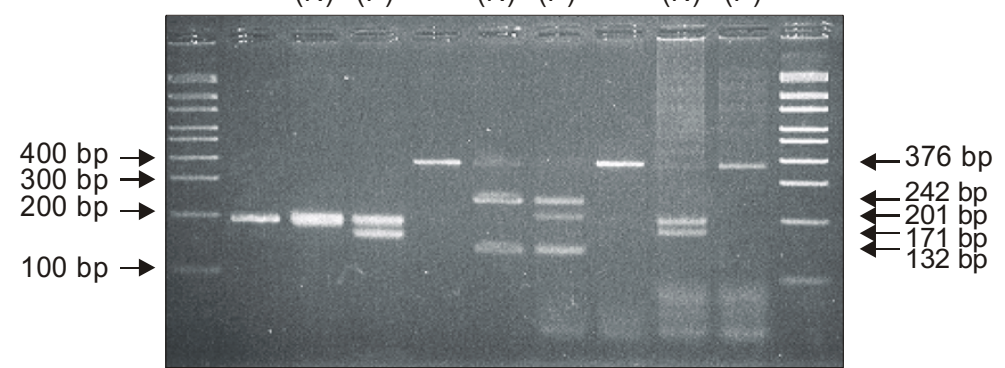

B

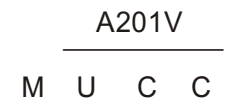

(P) $(\mathrm{N})$

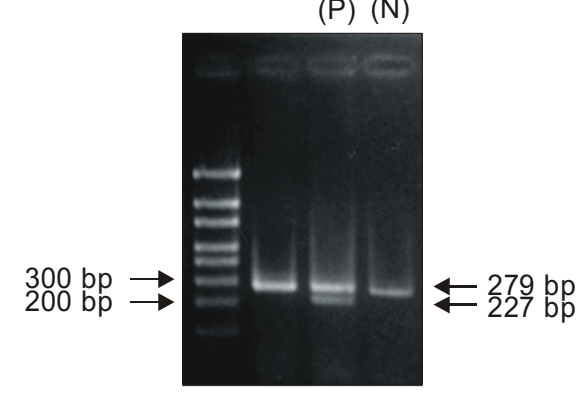

Figure 3. RFLP for novel mutations (G161E, T311M) and unclassified variants (L100V, A201V). Gel electrophoresis of PCR products before (U, uncut) and after ( $C$, cut) the restriction enzyme site. Cut samples are distinguished as normal controls $(N)$ and as mutations in patients $(P)$. (A) PCR product showing the part of exon 3 with a mismatch sequence (lane 1) and exon 4 (lane 4 and 7). The L100V mutation separated the 199 bp PCR product into $170 \mathrm{bp}$ and $29 \mathrm{bp}$ fragments by mutation-induced cleavage at the Afa I site. (lane 2 and 3) Dde I digestion created a $202 \mathrm{bp}$ and a $39 \mathrm{bp}$ fragment in G161E mutation (lane 5 and 6). T311M mutation identified by loss of the BsmB I site (lane 8 and 9). (B) A201V creates a Bal I restriction site. Normal controls have $279 \mathrm{bp}$ products and are not cleaved by Bal I digestion, while patients with A201V generated 229 bp and 52 bp fragments. Lane $\mathrm{M}$ is a $100 \mathrm{bp}$ molecular weight marker. The lower 60 bp products migrated off the gel. 
(366 bp) (Figure 3A, lane 9). The novel deletion mutation p385fs X409 (1153del44bp) was not identified by direct sequence mutational screening of exon 4 in the control samples. All of these base substitutions were absent in more than 100 control individuals. The RFLP and direct sequencing data indicate that these DNA variants are potential disease-causing mutations.

L100V (c.298C >G), one of these previously predicted substitutions, has been reported to be an unclassified variant associated with RTT (Buyse et al., 2000). Mismatch PCR was performed to determine whether L100V is also SNP in Korea. After amplification with the mismatch primers, the wild type sequence CCCTACCTGAA was generated. The generated mutant sequence CCG/TACCTGAA created an Afa I site. The 199 bp product was cut into pieces of $170 \mathrm{bp}$ and $29 \mathrm{bp}$ (Figure $3 \mathrm{~A}$, lane 2 and 3). Additionally, A201V (c.602C > T) has been reported to be a Japanese-specific characteristic because the mutation occurs in the normal Japanese population (Fukuda et al., 2005). The $279 \mathrm{bp}$ product with A201V was cut into $227 \mathrm{bp}$ and $52 \mathrm{bp}$ fragments by $B a l$ I (Figure 3B, lane 2 10). L100V and $A 201 \mathrm{~V}$ were absent in more than 100 normal control subjects and, therefore, were thought to be disease-causing mutations.

\section{Single nucleotide polymorphism (SNP) of the MECP2 gene}

IVS3 + 23C > G (g.C65494G) was observed in only three patients $(7 \%)$ (Figure 4$)$. The novel SNP accompanied other mutations in two of the patients.

\section{Discussion}

In classical cases, the mutation rate approaches $80 \%$ with lower rates in atypical cases $(30 \%)$ (Hoffbuhr et al., 2001). There is no clear correlation between the type and position of mutations, although MECP2 plays a pivotal role in the RTT phenotype (Weaving et al., 2003). We identified mutations of the MECP2 gene in $60.5 \%$ (26/43 cases) of the patients (Table 1). The mutational frequency was lower in our results than in previous studies due to the inclusion of patients with various phenotypes of RTT, and not limiting subjects to classical cases, as in previous reports. Most mutations were identified in the functional domains $(25 / 26,96.2 \%)$ MBD, TRD and WDR, and, therefore, probably critically affect the function of MECP2. We identified three novel mutations that cause amino acid substitutions (G161E, T311M, P385fsX409). G161E was found in MBD, T311M in TRD, and P385fs X409 in WDR of the C-terminus. The G161E substitution resulted in an alteration of a charge from neutral to negative
A

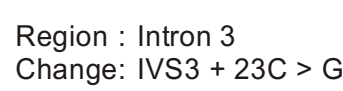

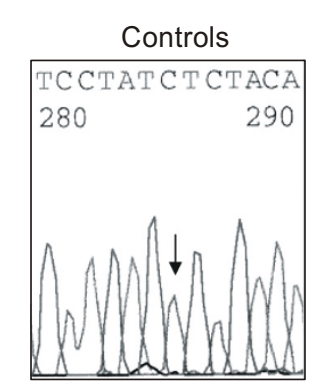

B

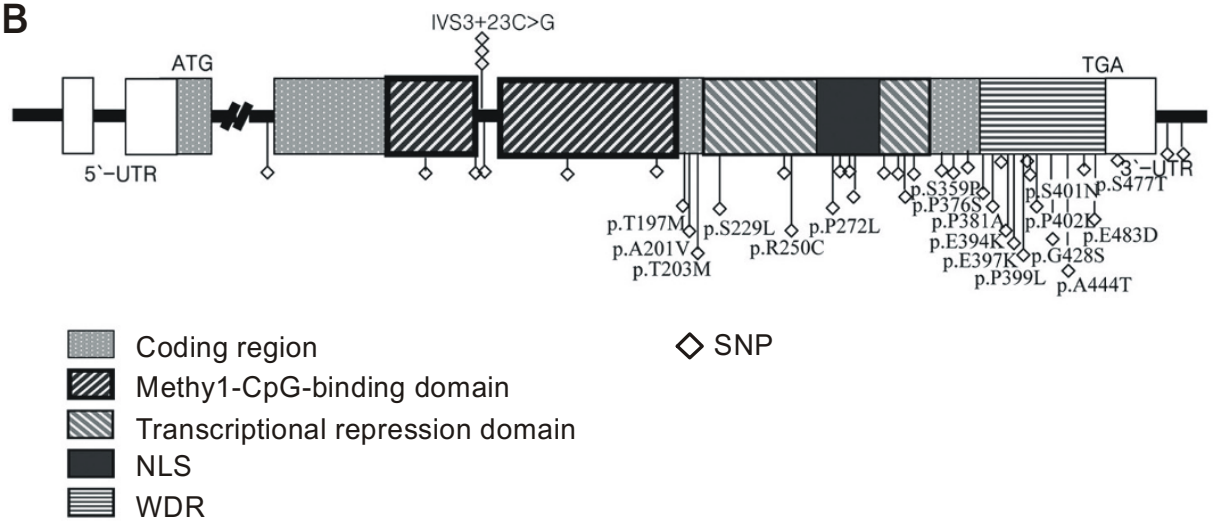

Figure 4. Single nucleotide polymorphism in the MECP2 gene identified by direct sequence analysis. (A) The substituted nucleotide is indicated by an arrow and the substituted codon is marked by underlining. All sequences are in the sense orientation. (B) Distribution of single nucleotide polymorphism in the $M E C P 2$ gene is identified. Top: The SNP identified in this study, Bottom: SNPs described by others (Buyse et al., 2000; Fukuda et al., 2005). 
and may reduce or abolish methyl-CpG binding. T311M probably causes the hydrophilic amino acid to be replaced by a hydrophobic one. P385fs X409 results in a reduction or loss of WW domain binding activity. The truncated mutation probably causes loss of the splicing factors FBP11 and HYPC that normally interact with WDR (Buschdorf and Stratling, 2004; Weaving et al., 2005). Hence, it may cause defective splicing that is involved with MECP2. These mutational results probably alter the properties of the protein. Twenty-two of the mutations $(22 / 26,84.6 \%)$ involved $\mathrm{C} \rightarrow \mathrm{T}$ transition at $\mathrm{CpG}$ dinucleotides. A clustering of mutations was identified in exon 4, except for L100V $(25 / 26,96.2 \%)$. Our findings strongly indicate that exon 4 should be sequenced first to screen for MECP2 mutations because the region is a hotspot for MECP2 mutations in RTT patients. Screening of two (exons 3 and 4 ) of the four exons will identify almost all gene mutations found in RTT patients, especially in Korean RTT patients.

To predict whether the observed changes were mutations or polymorphism, PCR-RFLP analysis of G161E and T311M was performed. Direct sequencing was used to analyze $P 385 f s X 409$. These mutations were not found in more than 100 control subjects. Therefore, G161E, T311M, and P385fsX409 are probably disease-causing mutations. Previous studies reported that L100V and A201V are the unclassified sequence and the SNP (Buyse et al., 2000; Fukuda et al., 2005), respectively. The alleles did not appear in more than 100 Korean control subjects. L100V and A201V were identified as possible disease-causing mutations from RFLP analysis in Korean RTT patients, which is contrary to previous reports. No mutation in MECP2 was found in the two male RTT patients in our study. Mutations in MECP2 in most males are lethal (Orrico et al., 2000). The infrequent occurrence of RTT in males has been explained by the existence of somatic mosaicism for an RTT-causing MECP2 mutation (Jellinger, 2003). We identified two silent mutations (F142F, T442T) and an intronic SNP (IVS3 + $23 \mathrm{C}>\mathrm{G}$ ) of the gene. The silent mutations are probably not responsible for the disease phenotype although they were associated with other mutations, except in one patient. IVS3 $+23 \mathrm{C}>\mathrm{G}$ was observed in only three RTT patients $(7 \%)$ and was not observed in control subjects. It is possible that IVS $3+$ $23 C>G$ is a disease-related and Korea-specific SNP for RTT. The novel SNP accompanied other mutations in two of the patients. This polymorphism probably results in phenotypic variability or susceptibility to RTT, even though it is an intronic SNP.

Mutation in MECP2 is not synonymous with RTT, and RTT is not always caused by an identifiable mutation in MECP2 (Miltenberger-Miltenyi and Laccone, 2003). Recently, studies have suggested a relationship between RTT and MECP2 in the regulation of UBE3A (Ubiquitin-Protein ligase E3A), GABRB3 (the beta3 subunit of the GABAA receptor) and CDKL5 (Cyclin-dependent kinase-like5) expression (Fan G and Hutnick L, 2005; Milani et al., 2005; Samaco et al., 2005; Segawa and Nomura, 2005). In this study, we did not detect any mutations of MECP2 in seventeen of the patients. These cases should be analyzed for mutations of other candidate genes, followed by functional analysis of these genes, as well as MECP2.

PCR-RFLP is an essential step in determining whether the observed changes to the MECP2 gene are mutations or polymorphisms. Disease-causing mutations and polymorphisms are important for diagnosing RTT in Koreans. The experimental procedures used in this study should be considered for molecular biologic diagnosis in the clinical field.

\section{Acknowledgement}

This study was supported by a Medical Research Institute Grant (2001-18) from Pusan National University Hospital.

\section{References}

Amir RE, Van den Veyver IB, Wan M, Tran CQ, Francke U, Zoghbi HY. Rett syndrome is caused by mutations in X-linked MECP2, encoding methyl-CpG-binding protein 2. Nat Genet 1999;23: 185-8

Bedia Agachan, Turgay Isbir, Hulya Yilmaz, Emel Ako ğu. Angiotensin converting enzyme $\mathrm{l} / \mathrm{D}$, angiotensinogen T174MM235T and angiotensin II type 1 receptor A1166C gene polymorphisms in Turkish hypertensive patients. Exp Mol Med 2003; 35:545-9

Buschdorf JP, Stratling WH. AWW domain binding region in methyl-CpG-binding protein MECP2: impact on Rett syndrome. J Mol Med 2004;82:135-43

Buyse IM, Fang P, Hoon KT, Amir RE, Zoghbi HY, Roa BB. Diagnostic testing for Rett syndrome by DHPLC and direct sequencing analysis of the MECP2 gene: identification of several novel mutations and polymorphisms. Am J Hum Genet 2000; 67:1428-36

Chae JH, Hwang YS, Kim KJ. Mutation analysis of MECP2 and clinical characterization in Korean patients with Rett syndrome. J Child Neurol 2002;17:33-6

den Dunnen JT, Antonarakis SE. Mutation nomenclature extensions and suggestions to describe complex mutations: a discussion. Hum Mutat 2000;15:7-12

den Dunnen JT, Antonarakis SE. Nomenclature for the description of human sequence variations. Hum Genet 2001;109: $121-4$ 
dos Santos JM, Abdalla CB, Campos M Jr, Santos-Reboucas $\mathrm{CB}$, Pimentel MM. The A140V mutation in the MECP2 gene is not a common etiological factor among Brazilian mentally retarded males. Neurosci Lett 2005;379:13-6

Fan G, Hutnick L. Methyl-CpG binding proteins in the nervous system. Cell Res 2005;15:255-61

Fukuda T, Yamashita Y, Nagamitsu S, Miyamoto K, Jin JJ, Ohmori I, Ohtsuka Y, Kuwajima K, Endo S, Iwai T, Yamagata H, Tabara Y, Miki T, Matsuishi T, Kondo I. Methyl-CpG binding protein 2 gene (MECP2) variations in Japanese patients with Rett syndrome: pathological mutations and polymorphisms. Brain Dev 2005; 27:211-7

Fyfe S, Cream A, de Klerk N, Christodoulou J, Leonard H. InterRett and RettBASE: International Rett Syndrome Association databases for Rett syndrome. J Child Neurol 2003; 18:709-13

Hoffbuhr K, Devaney JM, LaFleur B, Sirianni N, Scacheri C, Giron J, Schuette J, Innis J, Marino M, Philippart M, Narayanan V, Umansky R, Kronn D, Hoffman EP, Naidu S. MECP2 mutations in children with and without the phenotype of Rett syndrome. Neurology 2001;56:1486-95

Jellinger KA. Rett Syndrome--an update. J Neural Transm 2003;110:681-701

Jorgensen HF, Bird A. MECP2 and other methyl-CpG binding proteins. Ment Retard Dev Disabil Res Rev 2002;8:87-93

Lee SA, Kang DH, Nishio H, Lee MJ, Kim DH, Han WS, Yoo KY, Ahn SH, Choe KJ, Hirvonen A, Noh DY. Methylenetetrahydrofolate reductase polymorphism, diet, and breast cancer in Korean women. Exp Mol Med 2004;36:116-21

Milani D, Pantaleoni C, D'arrigo S, Selicorni A, Riva D. Another Patient With MECP2 Mutation Without Classic Rett Syndrome Phenotype. Pediatr Neurol 2005;32:355-7

Miltenberger-Miltenyi G, Laccone F. Mutations and polymorphisms in the human methyl CpG-binding protein MECP2. Hum Mutat 2003;22:107-15
Oexle K, Thamm-Mucke B, Mayer T, Tinschert S. Macrocephalic mental retardation associated with a novel C-terminal MECP2 frameshift deletion. Eur J Pediatr 2005;164:154-7

Orrico A, Lam C, Galli L, Dotti MT, Hayek G, Tong SF, Poon PM, Zappella M, Federico A, Sorrentino V. MECP2 mutation in male patients with non-specific X-linked mental retardation. FEBS Lett 2000;22:285-8

Reichwald K, Thiesen J, Wiehe T, Weitzel J, Poustka WA, Rosenthal A, Platzer M, Stratling WH, Kioschis P. Comparative sequence analysis of the MECP2-locus in human and mouse reveals new transcribed regions. Mamm Genome 2000;11: 182-90

Rett VA. Uber ein eigenartiges hirnatrophisches Syndrom bei Hyperammonamie im Kindesalter. Weiner Medizinische Wochenschrift 1966;37:723-6

Samaco RC, Hogart A, LaSalle JM. Epigenetic overlap in autism-spectrum neurodevelopmental disorders: MECP2 deficiency causes reduced expression of UBE3A and GABRB3. Hum Mol Genet 2005;14:483-92

Segawa M, Nomura Y. Rett syndrome. Curr Opin Neurol 2005; 18:97-104

Van den Veyver IB, Zoghbi HY. Methyl-CpG-binding protein $2 \mathrm{mu}-$ tations in Rett syndrome. Curr Opin Genet Dev 2000;10: 275-9

Weaving LS, Williamson SL, Bennetts B, Davis M, Ellaway CJ, Leonard $\mathrm{H}$, Thong MK, Delatycki M, Thompson EM, Laing N, Christodoulou J. Effects of MECP2 mutation type, location and $\mathrm{X}$-inactivation in modulating Rett syndrome phenotype. Am J Med Genet A 2003;118:103-14

Weaving LS, Ellaway CJ, Gecz J, Christodoulou J. Rett syndrome: clinical review and genetic update. J Med Genet 2005; 42:1-7 